Bangladesh Journal of Anatomy January 2014, Vol. 12, No. 1 pp. 25-29

\title{
Gross and Histomorphologic Study of the Umbilical Cord in Pre-gestational Diabetes Mellitus and Gestational Diabetes Mellitus
}

\author{
Md. Rafiqul Alam¹, Md. Abdul Momen², Anjuman Ara Sultana ${ }^{3}, \mathrm{SM}$ Nurul Hassan ${ }^{4}$
}

\begin{abstract}
Objective: The umbilical cord is fetal organ and contains two arteries and one vein covered by connective tissue called Wharton's jelly. Gestational diabetes mellitus (GDM) is a common metabolic disorder, the importance of which includes possible fetal and maternal complications. As the umbilical cord is the communicating channel between the fetus and the placenta, any pathological change in the umbilical cord may cause harm to the fetus. For this reason, some gross morphological and microscopic features of umbilical cord were analyzed in case of pre-gestational and gestational diabetes mellitus.

Materials and Methods: A cross-sectional, analytical and observational type of study was carried out in the Department of Anatomy, Bangabandhu Sheikh Mujib Medical University (BSMMU), Dhaka between July 2004 and December 2005. Total 60 umbilical cords with placentae were collected within 34 to 40 weeks of gestation from BSMMU and BIRDEM. Among these, twenty were from mothers not suffering from diabetes (Control group), twenty had pre-gestational diabetes mellitus (PDM group) and twenty were suffering from gestational diabetes mellitus (GDM group). Number of umbilical vessels were observed on the cut surface of umbilical cord later confirmed by histological examination. Presence or absence of true or false knots were noted. The umbilical cord cross sectional area, vessel areas and their luminal area were estimated. The ANOVA post-hoc option was used for statistical analyses of results.
\end{abstract}

Results: Among the gross and histomorphological variables of the umbilical cord, there was no significant difference between the three groups.

Key words: Umbilical cord, pre-gestational, gestational, diabetes mellitus.

\section{Introduction}

The umbilical cord contains two tubes of hypoblatic origin, the vitelline-intestinal and allantoic ducts, and their associated vitelline and allantoic (umbilical) blood vessels. In fact it is a combination of blood vessels in which the tunica adventitial coat is formed by Wharton's jelly. The umbilical cord has two-way

1. Associate Professor, Department of Anatomy, Dhaka Medical College, Dhaka

2. Assistant Professor, Department of Biochemistry, Ad-din Women's Medical College, Dhaka

3. Assistant Professor, Department of Anatomy, Shaheed Suhrawady Medical College, Dhaka

4. Professor \&Head Department of Anatomy, Monno Medical College, Manikganj.

Correspondence: Dr Md. Rafiqul Alam traffic: the arteries carry blood pumped by the heart away form the fetus and this circulation surrounds the vein normally. The umbilical vein returns blood to the fetus from the placenta rejuvenated with oxygen and nutrients and devoid of waste products ${ }^{1}$. It has been estimated that by 31 weeks, the umbilical cord must carry 70 quarts of blood per day, moving at 4 miles an hour. This remarkable organ also must participate in fetal growth milestones. Additionally, it may act as an assist pump to the fetal heart ${ }^{1}$.

Diabetes exerts a heavy toll on the vascular system. Vessels of all sizes are affected from the aorta down to the smallest arterioles and capillaries. The aorta and large size and medium size arteries suffer from accelerated severe atherosclerosis ${ }^{2}$. 
Gestational diabetes is important because of both its high prevalence and the possible fetal and maternal complications. According to Haver et al. ${ }^{3}$, approximately $2 \%$ to $3 \%$ of pregnancies are affected by diabetes mellitus, and $90 \%$ of them represent gestational diabetes mellitus. It has also been indicated that approximately $5 \%$ of all pregnancies are complicated by gestational diabetes mellitus ${ }^{4}$. The incidence of this disorder in our country is $6.7 \%$ of all pregnant mothers ${ }^{5}$. In western countries, the figure ranges from 0.15 to $12.3 \%{ }^{5}$. Maternal hyperglycemia leads to excess fetal insulin, which itself is a growth hormone for the fetus. Thus offspring of mothers with gestational diabetes mellitus have higher birth weight $^{6,7}$. In a microscopic study, Singh ${ }^{8}$ found rupture and erosion of the endothelial lining of the umbilical arteries that resulted in increased permeability and haemorrhages. He also found unduly dilated umbilical vein, disruption and degeneration of muscles fibres. Thus diabetes has effect on the gross morphology and also on the overall vascular structure of the umbilical cord.

Since the umbilical cord acts as a communicating channel between the uterine vasculature and the fetal vascular tree. And it is most likely that any condition that brings about any change in the uteroplacental vascular tree should have effect on these blood vessels too and this in turn might have effect on the wellbeing of the fetus

So, the present study was aimed at exploring the morphological features of the umbilical cord in pregestational and gestational diabetic conditions of the mother and quantifying some histological components of the umbilical cords in the study groups.

\section{Materials and Methods}

A total of 60 umbilical cords with placentae were collected. Of them, twenty specimens were collected from mothers with normal blood glucose level, tweenty from mothers suffering from pregestational diabetes mellitus and twenty were from mothers developing diabetes mellitus during the gestational period. Mothers with Rh-negative blood group, Positive VDRL test, Eclampsia, Preeclampsia, Positive HBs Ag test, Hypertension ,Multiple pregnancies (twin, triplet) ,Delivery of a stillborn baby were excluded from the study.

Cord diameter was measured with a metallic tape at the cut surface of the cord at a site about $10 \mathrm{~cm}$ from (distal to) its attachment with the placenta. Two readings were recorded one, the maximum diameter and the other was also maximum which was drawn at right angles to the maximum diameter. Then the mean of these two measurements was considered as the average diameter of the umbilical cord and it was expressed in millimetres.

One centimetre long tissue from the umbilical cord was processed for histological study. Steps in the processing of the tissue included fixation, dehydration, clearing, sectioning, staining and mounting .

The cross-sectional area of umbilical artery I, umbilical artery II and umbilical vein were all measured by the following equipments and materials.

Binocular microscope equipped with a drawing tube (Olympus model CH40, RF200), Stage micrometer, Drawing sheet, pencil and measuring scale, Light source for the drawing sheet and Computer with the software AutoCAD.

Tracing of the outline of the vessels were done by camera lucida drawing.

The traced vessel areas were scanned in to a computer and the areas were measured using the AutoCAD soft ware.

Area of the umbilical vessels were expressed in square millimetres $\left(\mathrm{mm}^{2}\right)$. The AutoCAD value was converted into real value by dividing the magnification times.

The luminal cross-sectional area of the umbilical vessels were measured by the same method like that of cross-sectional area of the umbilical vessels. 
Results:

Table-I

Results of the macroscopic variables of the umbilical cord

\begin{tabular}{lccccc}
\hline Variable & $\begin{array}{c}\text { Control } \\
\mathrm{n}=20\end{array}$ & $\begin{array}{c}\text { PDM } \\
\mathrm{n}=20\end{array}$ & $\begin{array}{c}\text { Significance of } \\
\text { difference } \\
\text { with Control }\end{array}$ & $\begin{array}{c}\text { GDM } \\
\mathrm{n}=20\end{array}$ & $\begin{array}{c}\text { Significance of } \\
\text { difference } \\
\text { with Control }\end{array}$ \\
\hline $\begin{array}{l}\text { Diameter of the cord }(\mathrm{mm}) \\
\text { Range }\end{array}$ & $\begin{array}{c}(7.6-14.5) \\
\text { Mean } \pm \text { SD }\end{array}$ & $\begin{array}{c}(10-13.5) \\
\text { Number of vessels }\end{array}$ & $\mathrm{NS}$ & $(8.5-13.5)$ & $\mathrm{NS}$ \\
$\begin{array}{l}\text { Artery } \\
\text { Vein }\end{array}$ & $11.20 \pm 1.77$ & $11.83 \pm 0.98$ & & $11.42 \pm 1.35$ & \\
True knot & 1 & 2 & $\mathrm{ND}$ & 2 & $\mathrm{ND}$ \\
False knot & Absent & Absent & ND & Absent & ND \\
\hline
\end{tabular}

PDM: Pre-gestational Diabetes Mellitus GDM: Gestational Diabetes Mellitus

The Post Hoc option of ANOVA (analysis of variance) was used to compare each group with every other group . $p \leq 0.05$ was considered as the level of significance. NS: Non-significant. ND: Significance test was not done..

Table II

Total cross-sectional area of the umbilical vessels in the three groups

\begin{tabular}{lccccc}
\hline Variable & $\begin{array}{c}\text { Control } \\
\mathrm{n}=20\end{array}$ & $\begin{array}{c}\text { PDM } \\
\mathrm{n}=20\end{array}$ & $\begin{array}{c}\text { Significance } \\
\text { of difference } \\
\text { with Control }\end{array}$ & $\begin{array}{c}\text { GDM } \\
\mathrm{n}=20\end{array}$ & $\begin{array}{c}\text { Significance of } \\
\text { difference } \\
\text { with Control }\end{array}$ \\
\hline Total vessel area(sq.mm) & & & & & \\
Range & $3.76-12.93$ & $3.61-10.36$ & NS & $\begin{array}{c}3.80-11.44 \\
6.47 \pm 1.86\end{array}$ & NS \\
Mean \pm SD & $7.16 \pm 2.69$ & $6.54 \pm 1.54$ & & & \\
\hline
\end{tabular}

PDM: Pre-gestational Diabetes Mellitus GDM: Gestational Diabetes Mellitus

The Post Hoc option of ANOVA (analysis of variance) was used to compare each group with every other group . $p \leq 0.05$ was considered as the level of significance. NS: Non-significant

Table III

Luminal cross-sectional area of the umbilical vessels in the three groups

\begin{tabular}{|c|c|c|c|c|c|}
\hline $\begin{array}{l}\text { Variable } \\
\text { n }\end{array}$ & $\begin{array}{l}\text { Control } \\
n=20\end{array}$ & $\begin{array}{l}\text { PDM } \\
n=20\end{array}$ & $\begin{array}{l}\text { Significance } \\
\text { of difference } \\
\text { with Control }\end{array}$ & $\begin{array}{l}\text { GDM } \\
n=20\end{array}$ & $\begin{array}{l}\text { Significance } \\
\text { of difference } \\
\text { with Control }\end{array}$ \\
\hline \multicolumn{6}{|c|}{ Lumen area UA-I (sq mm ) } \\
\hline Range & $(0.018-4.74)$ & $(0.01-0.18)$ & NS & $(0.03-0.46)$ & NS \\
\hline Mean \pm SD & $0.55 \pm 1.10$ & $0.08 \pm 0.05$ & & $0.11 \pm 0.11$ & \\
\hline \multicolumn{6}{|c|}{ Lumen area UA-II (sq mm) } \\
\hline Range & $(0.01-4.02)$ & $(0.006-0.38)$ & NS & $(0.008-0.13)$ & NS \\
\hline Mean \pm SD & $0.31 \pm 0.8$ & $0.063 \pm 0.08$ & & $0.06 \pm 0.03$ & \\
\hline \multicolumn{6}{|c|}{ Lumen area UV (sq mm) } \\
\hline Range & $(0.17-7.66)$ & $(0.08-3.44)$ & NS & $(0.15-2.08)$ & NS \\
\hline Mean \pm SD & $1.28 \pm 1.80$ & $1.02 \pm 0.92$ & & $0.71 \pm .44$ & \\
\hline
\end{tabular}

PDM: Pre-gestational Diabetes Mellitus GDM: Gestational Diabetes Mellitus UA-I: umbilical artery I,UA-II: umbilical artery II.UV: umbilical vein NS: Non Significant The Post Hoc option of ANOVA (analysis of variance) was used to compare each group with every other group $p \leq 0.05$ was considered as the level of significance. 


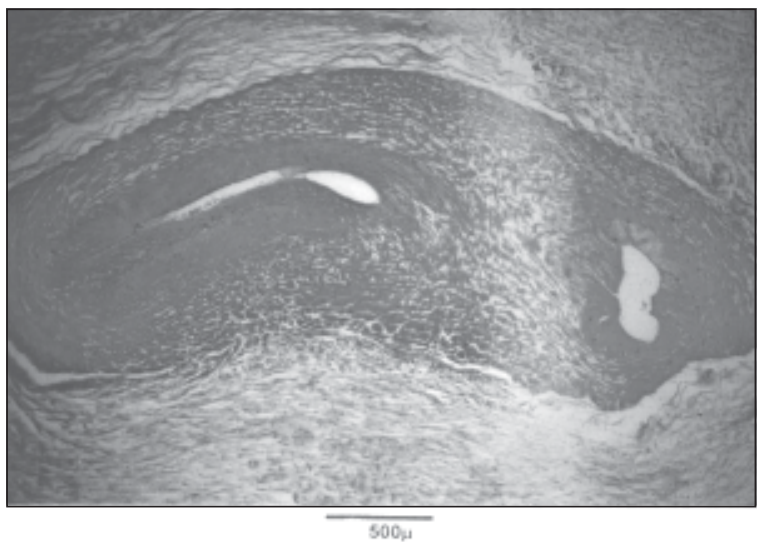

Fig.-1: Photomicrograph of a cross section of an umbilical cord of the GDM group showing two fused umbilical arteries. Stain: Mallory-Azan

\section{Discussion}

Normally two umbilical arteries and one umbilical vein are present in the umbilical cord.

One of the cord showed three umbilical arteries of which fusion had occurred between two through their media in the GDM group in the present study

Weissman and Jakobi ${ }^{7}$ in their study found that in pregnant patients with gestational diabetes mellitus, the umbilical cord was significantly larger in fetuses of mothers with gestational diabetes than in normal population . In the present study the mean diameter of the PDM $(11.83 \mathrm{~mm} \pm 0.98 \mathrm{~mm})$ group was higher than that of both GDM $(11.42 \pm 1.35 \mathrm{~mm})$ and Control $(11.2 \pm 1.77 \mathrm{~mm})$ group.

In the present study, the mean total cross-sectional area of the umbilical vessels in sq. $\mathrm{mm}$ are (7.16 \pm 2.69) Control group, (6.54 \pm 1.54$)$ PDM group and $(6.47 \pm 1.86)$ GDM group respectively. This indicates umbilical vessels have a tendency for dilatation and thinness in diabetic condition which coincides with the study of Singh ${ }^{8}$

Also, in the present study, the mean luminal crosssectional area of the umbilical vessels in sq. $\mathrm{mm}$ are UA-I, (0.55 \pm 1.10$)$ Control group, (0.08 \pm 0.05$)$ PDM group, (0.11 \pm 0.11$)$ GDM group. In UA-II (0.31 $\pm 0.8)$ Control group, (0.063 \pm 0.08$)$ PDM group, $(0.06 \pm 0.03)$ GDM group and in UV $(1.28 \pm 1.80)$

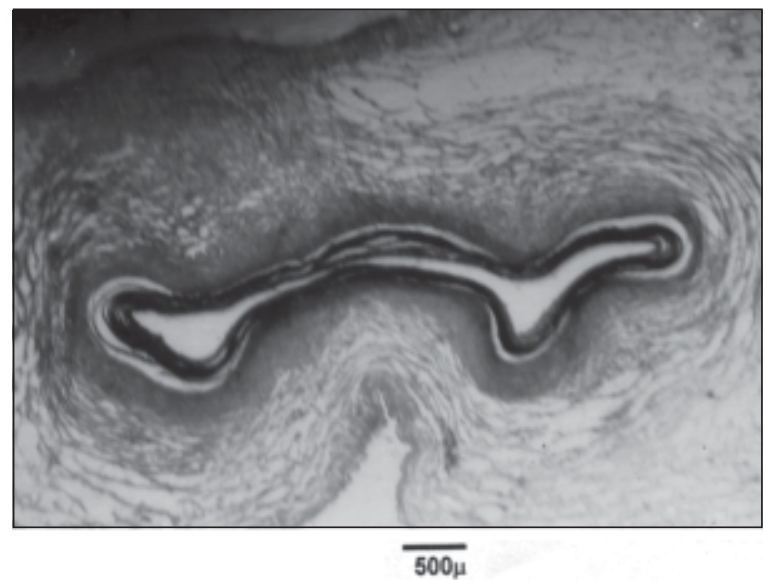

Fig. 2 Photomicrograph of a cross section of an umbilical cord of the PDM group showing a hugely dilated umbilical vein. Stain: Mallory-Azan

Control group, (1.02 \pm 0.92) PDM group, (0.71 \pm .44) GDM group respectively. But there was no significant difference between the three groups. The luminal cross-sectional area of umbilical vessels in both PDM and GDM group are narrower than that of Control group which is suggestive of atherosclerotic change $^{2}$ in the vessel wall.

Singh ${ }^{8}$ showed rupture and erosions of endothelial lining of umbilical arteries resulting in increased permeability of the vessels in diabetes. He also found unduly dilated umbilical vein. Such type of finding had been documented in this study In the present study too, the endothelium of a considerable number of blood vessels had erosion. In one of the cord a greatly dilated vein was observed.

\section{References}

1. Torpin R. Thermoplastic obstetrical forcepsobstetrical telemetry telemedicine current case study. Home-Prenatal Umbilical Cord Project- Virtual Birth Centre [online]. Available at: http: // www. Preg inst. Com/ chapter 1. html. 2002

2. Cotran RS, Kumar V, CollinsT. Robbins pathologic basis of disease. $6^{\text {th }}$ ed. London: WB Saunders Company. 2002

3. Haver MC, Locksmith GJ, Emmet E. Irregular menses: an independent risk factor for gestational diabetes mellitus. American 
Journal of Obstetrics \& Gynecology 2003; 188(5): 1189-91.

4. Veciana MD, Major CA, Morgan MA, Asrat T, Toohey JS, Lien MJ, et al. Postprandial versus preprandial blood glucose monitoring in women with gestational diabetes mellitus requiring insulin therapy. The New England Journal of Medicine 1995; 333(19):1237-41.

5. Barua R. Macroscopic and microscopic changes in human placenta in gestational diabetes and eclampsia. Thesis (M Phil). Bangabandhu Sheikh Mujib Medical University. 2002.
6. Gillman MW, Shman SR, Berkey CS, Field AE, Colditz GA. Maternal gestational diabetes, birth weight and adolescent obesity. Pediatrics 2003; 111: e221-e26.

7. Weissman A, Jakobi. Sonographic measurements of the umbilical cord in pregnancy complicated by gestational diabetes. Journal of Ultrasound in Medicine 1997; 16(10): 691-94.

8. Singh SD. Gestational diabetes and its effect on the umbilical cord. Early Human Development. 1986; 14(2): 89-98. 